\title{
Epidemiologia da poxvirose bovina no Estado do Espírito Santo, Brasil
}

Dirlei Molinari DONATELE ${ }^{1}$

Carlos Eurico Pires Ferreira TRAVASSOS ${ }^{1}$

Juliana de Almeida LEITE²

Erna Geessien KROON²

Correspondência para:

Dirlei Molinari Donatele

Laboratório de Sanidade Animal do CCTA-UENF

Av Alberto Lamego, 2000

Parque Califórnia, Campos dos

Goytacazes-RJ- 28013-600

e-mail: dirlei@uenf.br

Recebido para publicação: 21/11/2005 Aprovado para publicação: 10/05/2007

\author{
1 - Laboratório de Sanidade Animal do Centro de Ciências e Tecnologias \\ Agropecuárias da Universidade Estadual do Norte Fluminense Darcy Ribeiro, \\ Campos dos Goytacazes - RJ \\ 2 - Laboratório de Vírus do Instituto de Ciências Biológicas da Universidade \\ Federal de Minas Gerais, Belo Horizonte - MG
}

\section{Resumo}

O trabalho consistiu no estudo epidemiológico do surto de poxvirose bovina no Estado do Espírito Santo no período de 2002 a 2005. A coleta dos dados deu-se em 28 propriedades de gado bovino leiteiro de 08 municípios do Sul do Estado do Espírito Santo com casos de doenças pústulo-vesicular em bovinos, no período de agosto de 2002 a maio de 2005. Observou-se que a prevalência da doença no gado bovino leiteiro variou de $10,2 \%$ a $100 \%$ das propriedades com média de 52,7\%. Através de isolamento viral e PCR do gene Timidina Quinase (TK), identificou-se o vírus do gênero Orthopoxvirus como o agente etiológico da poxvirose bovina. Em todas as propriedades constatou-se uma perda econômica, principalmente relacionada à queda na produção leiteira. A poxvirose bovina assumiu um caráter epidêmico no Sul do Estado do Espírito Santo, com grande impacto econômico e importância em saúde pública, como uma zoonose ocupacional entre os ordenhadores. Baseadas nos dados obtidos, medidas de cunho fiscal-sanitário e de orientação ao produtor agropecuário foram implementadas, visando conter a disseminação da doença entres as propriedades, e os outros municípios do Estado.

\section{Introdução}

As poxviroses são doenças causadas por vírus da família Poxviridae, caracterizada pelos maiores e mais complexos vírus conhecidos, os quais se replicam no citoplasma de células de hospedeiros vertebrados e invertebrados, abrangendo um grande grupo de patógenos de importância médica e veterinária, principalmente os gêneros Orthopoxvirus e Parapoxvirus ${ }^{1}$.

A mão dos ordenhadores e os equipamentos de ordenha constituem as principais formas de transmissão da poxvirose entre os bovinos, com a penetração do vírus nas soluções de continuidade da pele e mucosa dos animais, principalmente na região dos tetos e úbere. A infecção dos humanos ocorre a partir das lesões existentes nos animais, durante o manejo e a retirada do leite dos bovinos ${ }^{2,3,4,5}$.

Tipicamente ocorre nas poxviroses a presença de lesões difusas na pele e mucosas que progridem de máculas para pápulas, vesículas e pústulas antes de formar crostas e cicatrizar, mas o diagnóstico clínico geralmente não é suficiente, tornando-se necessário estabelecer um diagnóstico laboratorial específico através: 1) Demonstração da partícula viral, do antígeno viral ou do ácido nucléico; 2) Demonstração do anticorpo antiviral; 3) Visualização das inclusões intracitoplasmaticas ${ }^{6,7}$.

A reação em cadeia da polimerase (PCR), constitui uma das principais técnicas de diagnóstico molecular na determinação dos agentes etiológicos das poxviroses, em especial para os gêneros Orthopoxvirus e Parapoxvirus, que são os principais agentes etiológicos da poxvirose bovina no mundo 
8,9. A caracterização molecular de um Orthopoxvirus, ocorre a partir de genes ou regiões subgenômicas conservadas do DNA viral, como os genes Timidina Quinase (TK) que são altamente conservados no genoma dos Orthopoxvirus e são responsáveis em codificar a timidina-quinase, uma enzima participante do metabolismo de ácidos nucléicos, tornando-se um gene amplamente utilizado na identificação de Orthopoxvirus ${ }^{5}$.

Nos últimos sete anos, inúmeros casos de doença pústulo-vesicular ocorreram em diversas propriedades leiteiras nos Estados do Rio de Janeiro, São Paulo e Minas Gerais acometendo o gado bovino leiteiro e humanos, principalmente ordenhadores e seus familiares. As características clínicas sugeriram a possibilidade de um agente etiológico da família Poxviridae, posteriormente comprovada por diagnóstico laboratorial como sendo um Orthopoxvirus. $\mathrm{Na}$ ocasião, Damaso et al. ${ }^{2}$ isolaram e caracterizaram molecularmente o vírus Cantagalo de crostas das lesões de bovinos na cidade de Cantagalo no Estado do Rio de Janeiro, Trindade et al. ${ }^{5}$, o vírus Araçatuba na cidade de Araçatuba no Estado de São Paulo, Leite ${ }^{10}$ o vírus Passatempo em Passatempo no Estado de Minas Gerais e Lobato et al. ${ }^{3}$ um Vaccinia-like virus em bovinos e humanos na Zona da Mata em Minas Gerais e Nagasse-Sugahara et al. ${ }^{4}$ um Vaccinia-like virus em humanos no Estado São Paulo e Goiás.

A partir de 2002, têm sido observados surtos de doença pústulo-vesicular no gado bovino leiteiro e humanos de propriedades leiteiras no Sul do Estado do Espírito Santo, com características clínicas semelhantes aos casos descritos nos Estados do Rio de Janeiro, São Paulo e Minas Gerais. Esses surtos vêm causando grandes prejuízos econômicos na agropecuária da região, com $100 \%$ dos bovinos acometidos em algumas propriedades, bem como a importância em saúde pública, como uma zoonose.

Objetivou-se, neste trabalho, realizar um estudo epidemiológico dos surtos das poxviroses no gado bovino leiteiro do Estado do Espírito Santo, identificando molecularmente o agente causador, bem como a adoção e divulgação das medidas de controle da doença junto aos órgãos responsáveis pela Sanidade Animal, Saúde Pública e aos proprietários de gado leiteiro.

\section{Material e Método}

\section{Distribuição das amostras e espécimens clínicos}

Coletou-se amostras de crostas das lesões de 47 bovinos durante as visitas nas 28 propriedades de gado leiteiro, com notificação de casos de doença pústulovesicular, distribuídas em oito municípios (Alegre, Atílio Vivacgua, Cachoeiro do Itapemirim, Castelo, Itapemirim, Piúma, Presidente Kennedy e Rio Novo do Sul) localizados no Sul do Estado do Espírito Santo, no período de agosto de 2002 a maio de 2005. Os bovinos das propriedades visitadas foram avaliados clinicamente, principalmente quanto à presença de lesões pústulo-vesiculares, e os dados anotados na ficha de investigação epidemiológica.

\section{Isolamento viral}

2.1. Ovo embrionado de galinha: As crostas dos 47 bovinos foram maceradas separadamente em solução salina fosfatada (PBS pH 7,2) acrescido com gentamicina $(100 \mathrm{mg} / \mathrm{L})$, anfotericina B $(5 \mathrm{mg} / \mathrm{L})$ e penicilina potássica ou sódica (400.000 U/L). A suspensão obtida foi coletada e centrifugada a $2790 \mathrm{x} \mathrm{g} \mathrm{a} 4^{\circ} \mathrm{C}$ por 5 min em Microcentrífuga. $100 \mu \mathrm{L}$ do sobrenadante foi inoculado na membrana corialantóide de ovos embrionados de galinha (MCA) com 10 dias de vida, com auxilio de uma seringa de $1 \mathrm{~mL}$ e agulha 13 x $0,4 \mathrm{~mm}$. Os ovos foram incubados a $37^{\circ} \mathrm{C}$ por 72 horas.

2.2. Cultura Celular: Cada amostra de MCA com lesão do tipo "pocks" foi macerada, com auxílio de um gral e areia fina autoclavada, em PBS acrescido com gentamicina $(100 \mathrm{mg} / \mathrm{L})$, anfotericina $B$ $(5 \mathrm{mg} / \mathrm{L})$ e penicilina potássica ou sódica (400.000 U/L). A suspensão obtida foi 
coletada e centrifugada a $2790 \mathrm{xg}$ a $4^{\circ} \mathrm{C}$ por 5 min em Microcentrífuga para obter a suspensão viral.

Células Vero cultivadas em monocamada em garrafas de cultivo celular de $50 \mathrm{~mL}$ (Corning ${ }^{\circledR}$ ) foram infectadas com $100 \mu \mathrm{L}$ da suspensão viral diluída em $1 \mathrm{~mL}$ de meio Auto-pow (MEM autoclavável da GibcoBRL), acrescido de gentamicina $(50 \mathrm{mg} / \mathrm{L})$, anfotericina B $(2,5 \mathrm{mg} / \mathrm{L})$ e penicilina potássica ou sódica $(200.000 \mathrm{U} /$ L). Após o período de 1 hora de adsorção em estufa a $37^{\circ} \mathrm{C}$, acrescentou-se $4 \mathrm{~mL}$ de meio Auto-pow suplementado com $1 \%$ de soro fetal bovino (SFB) e com antibióticos gentamicina $(50 \mathrm{mg} / \mathrm{L})$, anfotericina $B$ $(2,5 \mathrm{mg} / \mathrm{L})$ e penicilina potássica ou sódica (200.000 U/L). As culturas foram mantidas em estufa $37^{\circ} \mathrm{C}$ até o aparecimento de efeito citopático (ECP).

\section{PCR para Orthopoxvirus}

3.1. Extração de DNA viral: As extrações de DNA viral foram realizadas através da técnica do Fenol/Clorofórmio a partir dos extratos celulares (item 2.2.) ${ }^{11}$.

3.2. Amplificação do gene TK:. As regiões codificadoras do gene TK foram amplificadas por meio de reação em cadeia da polimerase (PCR), utilizando uma mistura padrão, contendo 30ng de DNA viral extraído, 20 pmoles de iniciadores específicos, $20 \mathrm{mM}$ de nucleotídeos (dATP, dCTP, dGTP, dTTP), $10 \mu \mathrm{L}$ de tampão Taq polimerase 10X, 1,5 $\mathrm{mM}$ de $\mathrm{MGCl} 2$, 2,5 U de Taq polimerase (Promega, USA) e $\mathrm{H}_{2} \mathrm{O}$ Milli Q, em um total de $20 \mu \mathrm{L}$ de reação. As amostras foram cobertas com óleo mineral estéril e o processamento foi realizado em aparelho Perkin Elmer Cetus (Perkin, USA) modelo N 801-150 ${ }^{10}$. Os oligonucleotídeos utilizados como iniciadores para a reação de PCR do gene TK foram desenhados por Fonseca et al. ${ }^{11}$ :

TK up:

5 , GCGAGGATCCAACGGCGGACATATTCAG 3'; TK low: 5' GCAGAAGCTTTGAGTCGATGTAACAC 3'.
As reações de PCR do gene TK foram programadas com base na metodologia descrita por Marques et al. ${ }^{8}: 01$ ciclo de $95^{\circ} \mathrm{C}$ por $5 \mathrm{~min}, 45^{\circ} \mathrm{C}$ por $1 \mathrm{~min} \mathrm{e}$ $72^{\circ} \mathrm{C}$ por $2 \mathrm{~min} ; 30$ ciclos de $95^{\circ} \mathrm{C}$ por 1 min, $45^{\circ} \mathrm{C}$ por 1 min e $72^{\circ} \mathrm{C}$ por 2 min; 01 ciclo de $94^{\circ} \mathrm{C}$ por $1 \mathrm{~min}, 45^{\circ} \mathrm{C}$ por $1 \mathrm{~min}$ e $72^{\circ} \mathrm{C}$ por $15 \mathrm{~min}$. Os fragmentos amplificados foram fracionados eletroforeticamente em gel de agarose $1 \%$, acrescido de $0,5 \mu \mathrm{g} / \mathrm{mL}$ de brometo de etídio, sob voltagem de $110 \mathrm{~V}$.

\section{Divulgação e controle do surto}

Estabeleceu-se uma parceria técnica entre a Universidade Estadual do Norte Fluminense Darcy Ribeiro (UENF), Universidade Federal do Espírito Santo (UFES), Instituto de Defesa Agropecuário e Florestal do ES (IDAF-ES) e Secretaria Estadual de Saúde (SESA), possibilitando, desta forma, a distribuição das informações sobre o surto e a identificação dos novos casos, com a participação dos produtores, da comunidade rural, dos Postos de Saúde e dos órgãos de Defesa Sanitária e Sanidade Animal do Estado do Espírito Santo.

\section{Resultados e Discussão}

Os 854 casos de poxvirose bovina notificados e estudados no Estado do Espírito Santo, que ocorreram no período de agosto de 2002 a maio de 2005 , estão distribuídos em 28 propriedades de gado de leite de oito municípios do Sul do Estado, como apresentado na figura 1 e na tabela 1. Os oito municípios encontram-se todos localizados na região de grande produção leiteira do Sul do Estado, próximos aos Estados do Rio de Janeiro e Minas Gerais onde foram notificados surtos de poxviroses bovina e humana, como descrito por Damaso et al. ${ }^{2}$ e Lobato et al. ${ }^{3,12}$. Essa proximidade poderia explicar em parte o aparecimento da doença no Estado e sua disseminação entre os municípios limítrofes, uma vez que a comercialização informal de animais entre os Estados e Municípios, sem o 
Tabela 1 - Prevalência da poxvirose no gado bovino leiteiro em propriedades localizadas no Sul do Estado do Espírito Santo, visitadas no período de agosto de 2002 a maio de 2005

\begin{tabular}{|c|c|c|c|c|}
\hline Município & $\begin{array}{l}\text { Propriedade } \\
\text { Leiteira }\end{array}$ & $\begin{array}{c}N^{\circ} \text { Bovino } \\
\text { de leite }\end{array}$ & $\begin{array}{c}N^{\circ} \text { bovinos clinicamente } \\
\text { doentes }\end{array}$ & *Prevalência - \% \\
\hline \multirow{11}{*}{ Alegre } & $\mathrm{A}_{01}$ & 58 & 44 & 75,9 \\
\hline & $\mathrm{A}_{02}$ & 40 & 35 & 87,5 \\
\hline & $\mathrm{A}_{03}$ & 45 & 35 & 77,8 \\
\hline & $\mathrm{A}_{04}$ & 30 & 28 & 93,3 \\
\hline & $\mathrm{A}_{05}$ & 13 & 12 & 92,3 \\
\hline & $\mathrm{A}_{06}$ & 34 & 23 & 67,6 \\
\hline & $\mathrm{A}_{07}$ & 12 & 12 & 100 \\
\hline & $\mathrm{A}_{08}$ & 50 & 30 & 60 \\
\hline & $\mathrm{A}_{09}$ & 60 & 50 & 83,3 \\
\hline & $\mathrm{A}_{10}$ & 40 & 30 & 75 \\
\hline & $\mathrm{A}_{11}$ & 25 & 10 & 40 \\
\hline \multicolumn{5}{|l|}{ Atílio } \\
\hline Vivacqua & $\mathrm{B}_{01}$ & 08 & 04 & 50 \\
\hline \multirow{7}{*}{$\begin{array}{l}\text { Cachoeiro de } \\
\text { Itapemirim }\end{array}$} & $\mathrm{C}_{01}$ & 212 & 80 & 37,7 \\
\hline & $\mathrm{C}_{02}$ & 70 & 35 & 50 \\
\hline & $\mathrm{C}_{03}$ & 60 & 20 & 33,3 \\
\hline & $\mathrm{C}_{04}$ & 30 & 27 & 90 \\
\hline & $\mathrm{C}_{05}$ & 40 & 36 & 90 \\
\hline & $\mathrm{C}_{06}$ & 26 & 03 & 11,5 \\
\hline & $\mathrm{C}_{07}$ & 60 & 10 & 16,6 \\
\hline Castelo & $\mathrm{D}_{01}$ & 30 & 30 & 100 \\
\hline Itapemirim & $\mathrm{E}_{01}$ & 32 & 28 & 87,5 \\
\hline Piúma & $\mathrm{F}_{01}$ & 30 & 06 & 20 \\
\hline \multirow{4}{*}{$\begin{array}{l}\text { Presidente } \\
\text { Kennedy }\end{array}$} & $\mathrm{G}_{01}$ & 48 & 30 & 62,5 \\
\hline & $\mathrm{G}_{02}$ & 80 & 40 & 50 \\
\hline & $\mathrm{G}_{03}$ & 256 & 103 & 40,2 \\
\hline & $\mathrm{G}_{04}$ & 170 & 80 & 47 \\
\hline Rio Novo do & $\mathrm{H}_{01}$ & 49 & 05 & 10,2 \\
\hline Sul & $\mathrm{H}_{02}$ & 12 & 08 & 66,7 \\
\hline Total & 28 & 1620 & 854 & 52,7 \\
\hline
\end{tabular}

* Os cálculos da prevalência foram realizadas no momento da visita em cada propriedade.

$\mathrm{A}_{\mathrm{n}}$ :Propriedades localizadas em Alegre; $\mathrm{B}_{\mathrm{n}}:$ Propriedade localizada em Atílio Vivacqua, $\mathrm{C}_{\mathrm{n}}$ :Propriedades localizadas em Cachoeiro de Itapemirim, $\mathrm{D}_{\mathrm{n}}:$ Propriedade localizada em Castelo, $\mathrm{E}_{\mathrm{n}}:$ Propriedade localizada em Itapemirim, $\mathrm{F}_{\mathrm{n}}:$ Propriedade localizada em Piúma, $G_{n^{0}}:$ Propriedades localizadas em Presidente Kennedy, $H_{n^{\circ}}$ :Propriedades localizadas em Rio Novo do Sul.

acompanhamento dos órgãos fiscalizadores, é uma prática comum entre as propriedades visitadas, bem como a utilização da mesma mão-de-obra (ordenhador) entre propriedades vizinhas, contribuindo na disseminação da doença, na qual 92,56\% $(\mathrm{n}=26)$ das 28 propriedades, observou-se a presença de ordenhadores com lesões pústulo-vesiculares semelhantes às observadas nos animais.
A maioria dos casos de poxvirose bovina no gado leiteiro no Sul do Espírito Santo teve início entre os meses de maio e setembro, sugerindo um caráter sazonal da doença, principalmente no período seco no Estado, época de maior traumatismo no úbere e tetos, favorecendo a disseminação do vírus no rebanho.

Observa-se, na tabela 1 , que a prevalência da poxvirose no gado leiteiro, 


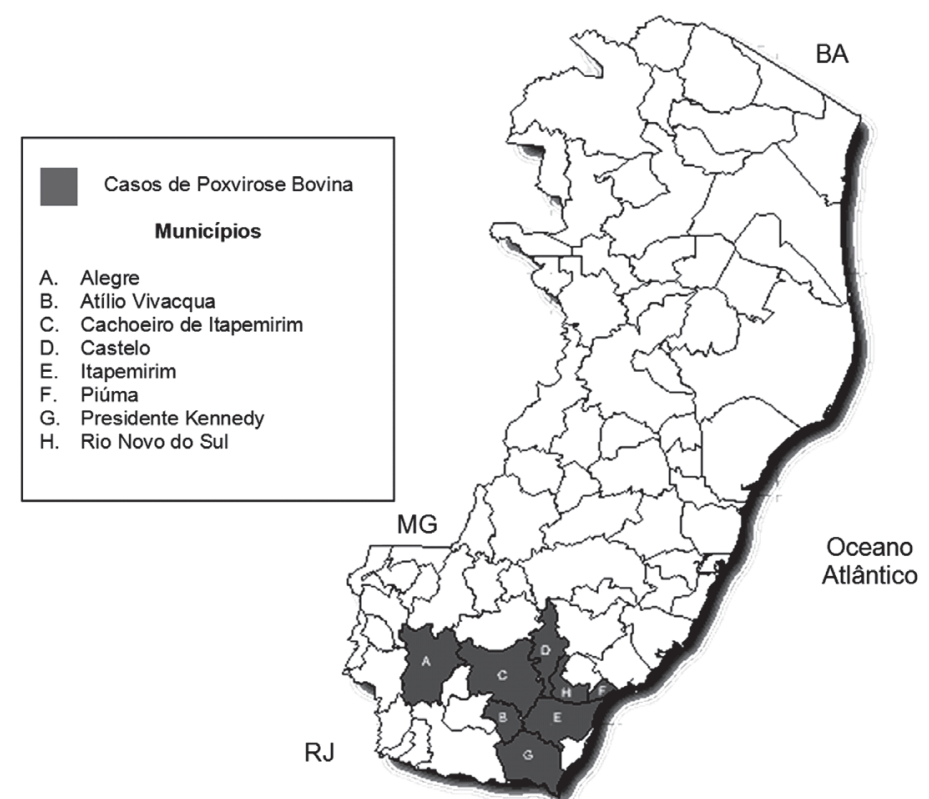

Figura 1 - Distribuição geográfica dos casos de poxvirose bovina e humana nos municípios do Estado do Espírito Santo, no período de agosto de 2002 a maio de 2005

variou entre 10,2 e $100 \%$ com média de $52,7 \%$, demonstrando a alta morbidade do vírus e o caráter epidêmico da doença, mesmo em propriedades com diferentes sistemas de manejos, como na fazenda $G_{04}$ possuidora de um grande rebanho leiteiro.

O quadro clínico da poxvirose no gado leiteiro do Espírito Santo consistiu basicamente de lesões pústulo-vesiculares cutâneas e dolorosas à palpação, geralmente múltiplas, localizadas principalmente nas tetas, com $94,85 \%$ dos animais apresentando lesões restritas nas tetas, $5,03 \%$ no úbere e teta e $0,12 \%$ na face.

$\mathrm{Na}$ fase inicial do desenvolvimento da doença, observou-se uma febre prodrômica irregular e uma dor à pressão da teta e úbere, as vesículas eram facilmente observadas, mas logo se rompiam, provavelmente pela ação mecânica da ordenha, formando uma ulceração, como mostrado na figura 2 , que progredia para crosta, e cicatrizava em média de 20 dias após os primeiros sinais. O quadro clínico da poxvirose bovina do gado leiteiro no Espírito Santo é compatível com outras poxviroses bovinas, como descrito por Murphy et al. ${ }^{9}$, Timms et al. ${ }^{13}$ e Weblen ${ }^{14}$, mas com rápida disseminação, como observado por Lobato et al. ${ }^{3,12}$.
Além da perda econômica com a queda na produção de leite, as propriedades tiveram prejuízos econômicos com o gasto com medicamentos, honorários de médicos veterinários, dificuldade na contratação de ordenhadores, pois os mesmos estavam receosos com a doença ou já estavam acometidos pela mesma.

Considerando a faixa etária e a raça dos animais acometidos, não é possível afirmar que existam diferenças de acometimento da doença entre as raças leiteiras e as faixas etárias dos animais, e sim com relação ao seu tipo de exploração, em que todos os animais eram bovinos leiteiros, destinados à produção de leite.

Todas as amostras de crostas foram maceradas e inoculadas na membrana corialantóide de ovos embrionados de galinha (MCA) com 10 dias de vida (MCA's), onde após 72 horas, todas as MCA's apresentaram lesões brancas e opacas, não hemorrágicas, característica de infecção por Orthopoxvirus, como descrito por Fenner, Wittek e Dumbell ${ }^{15}$ e observado por Trindade et al. ${ }^{5}$, conforme ilustrado na figura 3. A visualização deste efeito característico não só nos permitiu a confirmação da presença de um agente viral no material 


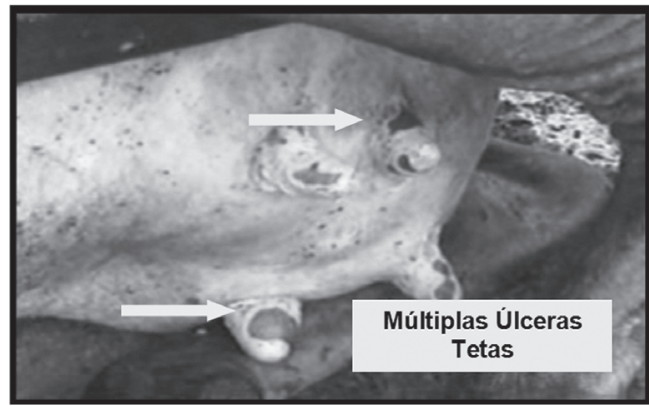

Figura 2 - Lesões ulcerativas nas tetas do gado leiteiro com poxvirose no Sul do Espírito Santo

obtido, como também a identificação inicial deste agente como um membro do gênero Orthopoxvirus, como causador do surto da poxvirose bovina no Sul do Estado do Espírito Santo.

As 47 suspensões virais obtidas em MCA foram utilizadas para infecção em células Vero em monocamada, sendo que 12 amostras dos diferentes municípios demonstraram ECP característico de vírus da Família Poxviridae.

Realizou-se a extração de DNA viral das 12 amostras que demonstraram ECP na monocamada das células Vero, para realização da técnica de PCR do gene TK, na qual todas as amostras amplificaram. Confirmando que o agente etiológico da poxvirose bovina do Sul do Estado do Espírito Santo é um vírus do gênero Orthopoxvirus, provavelmente um Vaccinia-like virus, como o vírus Cantagalo isolado por Damaso et $\mathrm{al.}^{2}$ das lesões de bovinos na cidade de Cantagalo no Estado do Rio de Janeiro, o vírus Araçatuba isolado por Trindade et $a .^{5}$ na cidade de Araçatuba no Estado de São Paulo e o vírus Passatempo isolado por Leite ${ }^{10}$ em Passatempo no Estado de Minas Gerais, Lobato et al. ${ }^{3}$ na Zona da Mata em Minas Gerais e NagasseSugahara et al..$^{4}$ em São Paulo e Goiás.

A rápida disseminação da doença dentro da propriedade e para outras propriedades, as características clínicas, caráter sazonal e os altos valores de prevalência da doença no gado leiteiro do Espírito Santo estão de acordo com o que fora relatado por Damaso et al. ${ }^{2}$, Leite ${ }^{10}$,Lobato et al. ${ }^{12}$, e Trindade et al. ${ }^{5}$ no gado

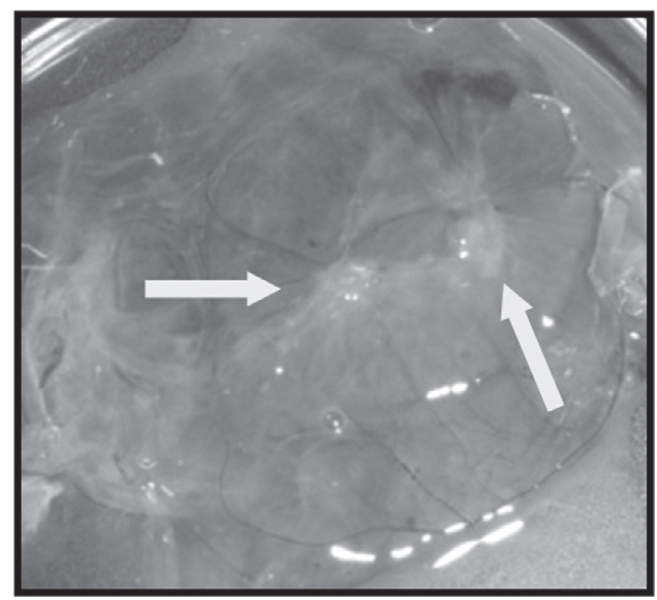

Figura 3 - Membrana Corioalantóde de embrião de galinha (MCA) com múltiplas lesões brancas e opacas, não hemorrágicas, com $72 \mathrm{~h}$ de incubação após inoculação com macerado de crosta de bovino

leiteiro nos Estados do Rio de Janeiro, Minas Gerais e São Paulo, evidenciam a inter-relação entre os agentes etiológicos desses surtos.

Essa confirmação de que mais um Estado do Brasil está sendo acometido por surto de Orthopoxvirus, com disseminação entre animais e humanos, sustenta a necessidade de mais pesquisas sobre o assunto, principalmente na identificação de possíveis reservatórios animais, da filogenética desses vírus, formas de disseminação da doença, impactos econômicos, risco para saúde pública e da implantação imediata de medidas de controle e prevenção dessa doença em todo o Brasil.

Estabeleceu-se uma parceria técnica entre a Universidade Estadual do Norte Fluminense Darcy Ribeiro, Universidade Federal do Espírito Santo, Instituto de Defesa Agropecuário e Florestal do Espírito Santo e Secretaria de Estado da Saúde, em que os casos suspeitos de poxvirose bovina fossem notificados e encaminhados ao Laboratório de Sanidade Animal/CCTA/ UENF para visita e constatação do caso. Essa parceria possibilitou uma maior abrangência, na notificação e detecção dos novos casos de poxvirose bovina no Estado do Espírito Santo, facilitando e melhorando a distribuição das informações, bem como o envolvimento dos Produtores, da Comunidade Rural, dos Postos de Saúde, das 
Secretarias Municipais de Saúde e os órgãos de Defesa Sanitária e Sanidade Animal do Estado do Espírito Santo, na divulgação das orientações sobre a doença.

As ações de controle basearam-se nos seguintes itens: a) Implementação da linha de ordenha nas fazendas, e a realização da desinfecção das ordenhadeiras e anti-sepsia das tetas e das mãos dos ordenhadores; b) Lavagem das tetas com água e sabão, e a imersão em solução de tintura alcoólica iodada a $2 \%$, após a ordenha; c) Evitar o trânsito na propriedade de pessoas, principalmente trabalhadores de outras propriedades; d) Examinar as tetas e o úbere antes da aquisição de animais de reposição; e) Proibição da comercialização dos animais das propriedades positivas; $f$ ) Quarentena dos animais recém adquiridos; g) Manter as tetas e úberes sadios; h) Promover a higiene de todas as instalações; i) Orientação aos funcionários e proprietários das propriedades sobre a doença e as suas medidas de controle; j) Divulgação da doença e do fluxograma de notificações via comunicado através dos órgãos de Defesa Sanitária Animal, Secretaria de Estado da Saúde e as Secretarias Municipais de Saúde.

\section{Conclusões}

O surto de poxvirose bovina foi causado por um Orthopoxvirus, provavelmente um Vaccinia-like virus, com alta morbidade e caráter epidêmico. As propriedades de gado de leite dos municípios localizados na região Sul do Espírito Santo encontram-se sob risco iminente do surto de Orthopoxvirus, na qual medidas de controle devem ser implementadas pelos órgãos responsáveis pela Sanidade Animal e Humana, visando o maior controle da doença, impedindo sua disseminação para outras regiões. Essa poxvirose bovina representa uma doença de grande importância econômica e de saúde pública.

\section{Epidemiology bovine poxviruse in the Espírito Santo State, Brazil}

\begin{abstract}
The purpose of this study was to investigate the epidemiological data of bovine poxviruses in the State of Espírito Santo during the years 2002 to 2005. The sample consisted of 28 properties that produce cow's milk in 08 cities from the South of the State, in wich were present cases of bonive pustulo-vesicular disease between 2002 august to 2005 may. The bovine disease was found in 10,2\% to $100 \%$ of the properties with a mean of $52,7 \%$. Throughout virus isolation techniques and PCR of the Timidin Kinase gene, an Orthopoxivirus was identified as the etiological agent of the bovine viruses. All the properties reported economic losts related to a decrease in milk production. The bovine poxviruses assumed an epidemic feature in the South of the State of Espírito Santo promoting a big economic impact and representing an important public health worry as an occupational zoonosis mainly for the milkers. Thus, based on the obtained data, policy and sanitary statements, and educational strategies, were applied in the properties in order to stop the disease dissemination over the neighbor cities.
\end{abstract}

Key words: Epidemiology. Bovine poxviruses. Orthopoxvirus. 


\section{Referências}

1 MOSS, B. Poxviridae: the viruses and their replication. In: FIELDS, B. N.; KNIPE, D. M.; HOWLEY, P. M. (Ed.). Fields virology. 3. ed. Philadelphia: Lippincott-Raven, 1996. p. 2637-2671.

2 DAMASO, C. R. A. et al. An emergent poxvirus from humans and cattle in Rio de Janeiro State: Cantagalo Virus may derive from Brazilian smallpox vaccine. Virology, n. 277, p. 439-449, 2000.

3 LOBATO, Z. I. P. et al. Surto de varíola bovina causada pelo vírus Vaccinia na região da Zona da Mata Mineira. Arquivo Brasileiro de Medicina Veterinária e Zootecnia, v. 57, n. 4, p. 423-429, 2005.

4 NAGASSE-SUGAHARA, T. K. et al. Human vaccinialike virus outbreaks in São Paulo and Goiás states, Brazil: virus detection, isolation and identification. Revista do Instituto de Medicina Tropical de São Paulo, n. 46, p. 315-322, 2004.

5 TRINDADE, G. S. et al. Araçatuba Virus: A vaccinialike virus associted with infection in humans and cattle. Emerging Infectious Diseases, n. 9, p. 155-160, 2003.

6 ACHA, P. N.; SZYFRES, B. Virosis. In: ACHA, P. N. SZYFRES, B. Zoonosis y enfermedades transmisibles comunes al hombre y a los animales. 2. ed. Washington, D.C.: Organizacion Panamericana de la Salud, 1986. p. 297-551. (publicación cientifica, n. 503)

7 IKETANI, Y. et al. Persistent parapoxvirus infection in cattle. Microbiology and Immunology, n. 46, p. 285291, 2002.

8 MARQUES, J. T. et al. Caracterization of ATI, TK, and
IFN-á/âR genes in the BeAn 58058 virus, a naturally attenuatted wild Orthopoxvirus. Virus Genes, n. 23, p. 291-301, 2001.

9 MURPHY, F. A. et al. Poxviridae. In: MURPHY, F. A.; GIBBS, E. P. J.; HORZINEK, M. C.; STUDDERT, M. J. (Ed.). Veterinary virology. 3. ed. San Diego: Academic Press, 1999. p. 277-291.

10 LEITE, J.A. Isolamento, identificação e caracterização molecular de Orthopoxvirus isolados em um surto de varíola bovina em Passatempo-MG. Dissertação (Mestrado em Microbiologia). 2003. 83f. Departamento de Microbiologia do Instituto de Ciências Biológicas da UFMG, Belo Horizonte, 2003.

11 FONSECA, F. G. et al. Morphological and molecular characterization of the poxvirus BeAn 58058. Archives of Virology, n. 143, p. 1171-1186, 1998.

12 LOBATO, Z. I. P. et al. Varíola bovina: zoonose reemergente avança em Minas Gerais. V\&Z em Minas. Revista do Conselho Regional de Medicina Veterinária de Minas Gerais, n. 83, p. 18-20, 2004.

13 TIMMS, L. I. et al. Histologic features and results of virus isolation tests tissues obtained from teat lesions that developed in dairy cattle during winter. Journal of the Americam Veterinary Medical Association, n. 213 p. 862-865, 1998.

14 WEBLEN, R. Vaccínia - varíola bovina e pseudovaríola. Revista CFMV, Brasília, n. 26, p. 37-43, 2002.

15 FENNER, F.; WITTEK, R.; DUMBELL, K. R. The global spread, control and eradication of smallpox. In: The orthopoxviruses. San Diego: Academic Press, 1989. p. 317-352. 